\title{
THE EFFECTS OF INCENTIVE SYSTEMS AND ORGANIZATIONAL CULTURE ON STRATEGY SURROGATION
}

\author{
Kazeem Olalekan Akinyele \\ University of Wisconsin Oshkosh, United States \\ E-mail: akinyelk@uwosh.edu
}

\begin{abstract}
The purpose of this study was to investigate the impact of an important aspect of an organizational context, specifically organizational culture, and different types of compensation schemes on strategy surrogation. Strategy surrogation occurs when managers focus on the measures in the strategic performance measurement systems (SPMS) on which they are compensated and completely or partially lose focus on the overall strategic objectives of the organization. This study utilized a $2 \times 2$ between-participants experimental design that manipulates organizational culture (controldominant vs. flexibility-dominant) and the type of compensation scheme (fixed pay vs. pay-for-performance). The study was conducted online with 80 participants from the Amazon Mechanical Turk (MTurk) as proxies for managers. The results show that employees operating under a controldominant culture do not surrogate more than employees operating under a flexibility-dominant culture. Additionally, the type of organizational culture does not moderate the relationship between incentive systems and strategy surrogation. However, employees operating under a pay-for-performance compensation scheme significantly surrogate more than employees operating under a fixed pay compensation scheme. The study contributes to the incentives and organizational culture literature as well as strategy surrogation research by examining institutional factors that may inhibit or exacerbate surrogation. Additionally, the study contributes to the judgment and decision-making literature by highlighting employees' decision-making outcomes under different compensation schemes.
\end{abstract}

Keywords: organizational culture, incentive systems, strategy surrogation, informal management control system

ARTICLE INFO

Article History:

Received: 8 October 2018

Accepted: 28 March 2019

Published: 30 April 2019 


\section{INTRODUCTION}

Strategy surrogation has been identified as one of the possible unintended consequences of the use of a Strategic Performance Measurement Systems (SPMS) (Choi, Hecht \& Tayler, 2012, 2013). Strategy surrogation occurs when managers focus on the measures in the SPMS on which they are compensated and completely or partially lose focus on the overall strategic objectives of the organization (Choi et al., 2012, 2013). For example, consider a firm pursuing a customer-focused strategy and measuring customer satisfaction using a satisfaction survey score. Choi et al. (2013) argue "to the extent that those scores imperfectly measure customer satisfaction, managers' strategy-related judgments and decisions may be flawed if they surrogated customer satisfaction with the survey scores" (p. 106).

The purpose of this research was to investigate the impact of an important aspect of organizational context, specifically organizational culture, and different types of compensation schemes on strategy surrogation. Organizational culture is defined as a set of dominant values, beliefs, and assumptions that govern how people behave in organizations (Henri, 2006). According to the competing values model, organizational culture can be characterized as either control-dominant, which values stability and accountability, or flexibility-dominant, which values invention and innovation (Quinn \& McGrath, 1985; Quinn, 1988; Quinn \& Rohrbaugh, 1983). This study examined the impact of each of these cultural characterizations on strategy surrogation. Furthermore, the study builds on the prior work by Choi et al. (2012) by investigating whether the type of organizational culture, flexibility- or control-dominant, exacerbates or mitigates the impact of compensation scheme on strategy surrogation.

According to the Inattentional Blindness Theory, when individuals concentrate on a particular object or event, they often fail to notice other relevant and distinctive objects of interest that are located outside their field of focus. Using this theory, this study proposes that individuals operating in a control-dominant organizational culture will exhibit more strategy surrogation than individuals operating in a flexibility-dominant organizational culture. In a control-dominant culture, individuals may be more blinded toward an overall strategic objective and less motivated to 
look beyond the performance metric, as what gets measured will receive the most attention (Burney \& Widener, 2013). Additionally, this study predicts that when individuals are paid for performance, they are motivated to meet or exceed performance targets and have little or no incentive to look beyond these metrics. Thus, individuals paid for performance will exhibit more surrogation than individuals paid a fixed wage. Finally, this study predicts that a flexibility-dominant culture will reduce strategy surrogation more under a fixed pay scheme than a pay-for-performance scheme compared to a control-dominant culture.

This research used a 2 (culture: control-dominant vs. flexibilitydominant) x 2 (compensation scheme: fixed pay vs. pay-for-performance) between-participants experimental design. To examine the hypotheses in this study, an online experiment was conducted using 80 Amazon Mechanical Turk (MTurk) workers as proxies for managers. The study consisted of two parts. In the first part, the participants were asked to read a short case scenario, and at the end of the case, they were asked to make some decisions. In the second part, participants were asked several postexperimental questions and demographic questions. The participants were randomly assigned to four conditions. All participants were paid $\$ 2.50$ for participating, and additional research compensation up to a total of $\$ 9.00$ depending on their randomly assigned condition and their decisions.

The results suggest that the type of organizational culture does not influence managers' propensity to exhibit strategy surrogation. Specifically, managers operating in a control-dominant organizational culture do not exhibit more strategy surrogation than managers operating in a flexibilitydominant organizational culture. However, the results show that the type of compensation scheme strongly influences employees' tendency to exhibit strategy surrogation. Specifically, the results indicate that employees compensated using a pay-for-performance compensation scheme have a higher tendency to use the measures of SPMS as a surrogate for strategy constructs than the employees compensated using a fixed pay scheme. This result is in support of the Inattentional Blindness Theory. These results imply that employees operating under a pay-for-performance scheme will be less likely to notice relevant information that is beyond their current focus when making decisions compared to employees operating under a fixed pay scheme. 
This study contributes to research and practice in several ways. First, this study contributes to prior research by exploring whether organizational culture, as a form of informal management control system, influences strategy surrogation. There has been limited research examining informal management control systems from the organizational culture perspective (Dent, 1991; Henri, 2006). The results show that organizational culture does not influence surrogation. However, there could be some other institutional factors that influence surrogation. Second, the result shows that employees compensated under a pay-for-performance scheme significantly surrogate more than employees compensated under a fixed pay scheme. The results corroborate prior research findings in managerial accounting on strategy surrogation. Overall, this study contributes to the incentives literature by highlighting conditions under which incentive systems can be used to refocus employees' attention.

The paper proceeds as follows: The next section discusses the literature and hypotheses development, section III discusses the experimental method and design, section IV provides the results, and section $\mathrm{V}$ discusses the conclusion and opportunities for future research.

\section{BACKGROUND LITERATURE AND HYPOTHESES DEVELOPMENT}

\section{Surrogation}

"The primary purpose of measurement is to communicate the state of other things. Figures produced as an output of measurement have no utility in themselves apart from their function to represent the state of other objects. Things or phenomena that are used to convey information about the state of something else are called surrogates."

(Ijiri 1975, p. 40)

Surrogation often occurs because perfectly capturing the construct of interest is difficult in reality (Ijiri, 1975). For example, prior literature shows that accounting measurement provides only a surrogate or symbolic representation of the economic reality in an organization, while 
decision makers are interested in the underlying reality (Bedford, 1968). Measurement is defined as a special language that signifies real-world phenomena by means of numbers and the relations among those numbers that are predetermined within the number system (Ijiri, 1975). The purpose of measurement is not just to capture the figures, but also "to represent a given relation(s) among objects by predetermined relation(s) among the numbers" (Bedford, 1968, p. 272). Hence, an individual may think that measurement is the end, and fails to understand that it is just the means to an end, which may result in surrogation (Ijiri, 1975).

\section{Strategy Surrogation}

Strategic Performance Measurement Systems (SPMS) have been described as any system in which there is a link between financial and nonfinancial performance measures and strategy in order to align individual actions within an organization with the organization's strategy (Webb, 2004). Although aligning individual actions with organizational strategy is important, transparency in performance measurement systems has been identified as one of the keys to a functioning and effective SPMS (Kaplan \& Norton, 1996). Managers ideally should be able to "see through" the metrics of measurement of a strategically linked performance measurement system (Kaplan \& Norton, 1992), because a perfect measure of the construct of interest is rare (Choi et al., 2012). When performance metrics are difficult to "see through" (Kaplan \& Norton, 2000) and the performance goals often are difficult to achieve (Webb, 2004), utilization of the SPMS may result in strategy surrogation (Choi et al., 2012, 2013).

According to Choi et al. (2012), strategy surrogation occurs in SPMS when individuals in an organization "fail to fully appreciate the fact that measures are merely representations of strategic constructs, and act as though the measures are the constructs of interest" (p.1135). To completely capture a construct of interest in an SPMS is practically impossible. For example, university administration may try to capture the strategic construct of teaching effectiveness through student evaluations; however, because the faculty members are aware that their performance evaluation will depend on students' perceptions, they may decide to give students higher grades towards the end of the semester in order to get a better evaluation. In this example, the faculty members have surrogated the students' evaluations 
for teaching effectiveness. This study explores whether institutional factors such as organizational culture could be used to encourage or discourage managers from exhibiting such dysfunctional behavior.

Limited studies have examined this important concept of strategy surrogation in accounting. Choi et al. (2012) examined whether and how the use of strategically linked performance measures for compensation purpose affects managers' propensity to exhibit strategy surrogation. Drawing upon the Attribute Substitution Theory, their study showed that when managers' compensation is based on a single measure of a strategic construct of interest, managers are more likely to surrogate than when the compensation is based on multiple measures of a strategic construct. Surrogation often occurs in a complex and fast paced decision-making environment in an organization, where managers often rely on an easily accessible heuristic for their judgment and decision-making (Kahneman \& Egan, 2011). Hence, managers has a tendency to attach more value to a singular measure of a strategic construct compared to multiple measures, especially when it is easier for them to focus on more salient items (Kahneman \& Egan, 2011; Simons, 2000).

In a similar manner, Choi et al. (2013) examined how managers' involvement in strategy surrogation influences their propensity to surrogate strategic constructs with compensated measures. Their study suggests that in order to mitigate the impact of strategy surrogation in an organization, managers must be involved in choosing strategy measures. They demonstrate that managers' involvement in strategy deliberation without involvement strategy selection may not necessarily reduce surrogation. Considering the importance of the SPMS in an organization (Campbell et al., 2015; Chenhall, 2005; Dent, 1990) and the potential hindering effect of strategy surrogation on the effectiveness of SPMS (Choi et al., 2013), prior research has called for future research that examines other institutional factors that possibly could inhibit or exacerbate strategy surrogation (Choi et al., 2012).

\section{Organizational Culture}

Organizational culture and management style appear to be interdependent throughout the lifecycle of a performance measurement system; and this interdependency is dynamic in nature (Bititci et al., 2006). 
Management style needs to evolve as the life cycle of the performance measurement system and organizational culture evolves (Bititci et al., 2006). For an organization to compete in a competitive, dynamic, and global environment, the organization must be willing to develop and implement performance measurement systems that lead to a participative and consultative management style and organizational culture. Such an organizational culture also must support implementation and the operating effectiveness of performance measurement systems (Bititci et al., 2006). Bititci et al. (2012) have called for future research to obtain a better understanding of management style and organizational culture that would facilitate the implementation of SPMS.

Performance measures play an important role in motivating employees to achieve organizational goals (Bititci et al., 2012; Ittner \& Larcker, 1998); however, prior studies have shown that work-place environments influence the relationship between the effectiveness of performance measurements and employee outcomes (Cravens, Oliver \& Stewart, 2015). Considering the interplay between organizational culture and effectiveness of performance measurements, certain performance measurements and management styles may be counterproductive to overall organizational goals in a particular organizational culture (Bititci et al., 2012). The initial belief that organizations that are managed through measures perform better is now being challenged (Bititci et al., 2006; Johnson \& Broms, 2000). Johnson and Broms (2000) show that organizations should move beyond "managing by results" to "managing by means." Thus, organizations should encourage systemic thinking among their employees rather than drive work with only financial targets (Johnson \& Broms, 2000). The managing-by-means environment creates a flexible, enjoyable, and more productive working condition; the managing-by-results environment leads to a controlling work environment, which may not necessarily lead to an increase in productivity (Johnson \& Broms, 2000). One important institutional factor that could impact the effectiveness of the SPMS in an organization is the values and culture of the organization (Bititci et al., 2006).

Henri (2006) described organizational culture as "the shared values (what is important) that interact with an organization's structures and control systems to produce behavioral norms (the way we do things around here)" (p. 79). The deinition of an organizational culture is broad in the management 
and accounting literature; however, this study draws upon the competing values model of organizational culture (Henri, 2006; Quinn \& McGrath, $1985)$ to examine strategy surrogation. Organizational culture is an important concept because it can either motivate or demotivate employees to achieve overall organizational goals (Bititci et al., 2006; Bititci et al., 2012; Choi et al., 2012, 2013). Although managing-by-results is a form of a management control system that is synonymous with terms such as formality, rigidity, and conformity, it may not necessarily lead to an increase in productivity (Henri, 2006; Johnson \& Broms, 2000). Managing-by-means is an inspirational method of encouraging employees to realize extraordinary results in a sustainable way, which is synonymous with terms such as adaptability, spontaneity, and responsiveness (Henri, 2006; Johnson \& Broms, 2000).

Quinn and McGrath (1985) developed the Competing Values Model of organizational culture. The model consists of four quadrants that represent four different organizational cultures and their embedded theories of effectiveness: rational, consensual, hierarchical, and developmental cultures. From these four quadrants, the flexibility/control axes and internal/external focus axes emerge. For the purpose of this study, the current focus will be on the flexibility and control axes because the goal of this study is to examine how the trade-offs between flexibility (which could improve invention and innovation) and control (which could improve stability and accountability) affect strategy surrogation (Quinn \& McGrath, 1985).

From a practical perspective, neither absolute flexibility nor absolute control exists in any organization (Henri, 2006). Establishing absolute flexibility in an organization leads to disorderliness, instability, and chaos. At the same time, establishing absolute control discourages novelty, inspiration, and creativity. In every organization, an element of flexibility and controlling values exists (Quinn, 1988). Hence, Henri (2006) explicitly states that the "distinction between cultural types associated with control and flexibility values is not a dichotomous split but instead the extremes of control/ flexibility continuum" (p. 80). This study, similar to Henri (2006), refers to control values organizations as organizations reflecting a control-dominant culture, and flexibility values organizations as organizations reflecting a flexibility-dominant culture. For example, working in public accounting can be used to illustrate a control-dominant cultural environment where auditors must strictly follow the audit program when carrying out the audit process. 
In this type of environment, auditors easily can surrogate the audit program for a quality audit, not realizing that it is merely providing guidance; the audit program does not necessarily translate to audit quality because it is the minimum requirement. In contrast, managers working in an environment where there is no formality or rigidity will have a different perspective to the metrics of their performance measurements. The managers will tend to see that performance metrics are used to provide mere guidance, which implies that they provide a means to the end, but not to the end itself. This type of cultural environments can be referred to as a flexibility-dominant culture.

Psychology theory on attention capture has found that when individuals concentrate on another object, event, or thing, they often fail to notice salient, distinctive, and unexpected events around them, a phenomenon known as inattentional blindness (Simons, 2000). For example, a driver may fail to notice a pedestrian while trying to make a right turn at a red stop light because his/her focus is on the red light, or a person may fail to notice a friend in the cinema while trying to find an empty seat because he/she is not paying attention to anything in the cinema hall other than the empty seat (Simons \& Chabris, 1999; Simons, 2000). Traditional attention capture in psychology literature can be divided broadly into two categories: implicit attentional capture and explicit attentional capture. Implicit attentional capture is a situation where an observer is able to ignore something he/she expects, but knows to be irrelevant. However, explicit attentional capture, also known as inattentional blindness, is a situation where an observer fails to notice something that is potentially relevant, but that he/she does not expect (Simons, 2000).

Choi et al. (2012) define strategy surrogation as the inability of managers to realize that performance measures are merely representations of strategic constructs and to assume that these measures are the constructs of interest. Choi et al. (2012) suggest that future research should examine other institutional factors that could inhibit or exacerbate strategy surrogation. The type of cultural environment is one of those factors that could influence managers' propensity to surrogate. In a cultural environment that is controldominant, managers may find it difficult to consider salient and potentially relevant information when making decisions compared to managers that operate in a flexibility-dominant environment. Due to rigidity, formality, and conformity characteristics of a control-dominant culture, managers may 
demonstrate a greater tendency to over focus on the performance measures and lose focus of underlying constructs of interest, which the performance measures are representing. Alternatively, considering the responsiveness, adaptability, and spontaneity characteristics of the flexibility-dominant environment, managers may have more incentive to see beyond the performance measures; hence, they may be less likely to ignore salient and potentially relevant information than managers in a control-dominant organizational culture. Using the Inattentional Blindness Theory, the following hypothesis is proposed:

$\mathbf{H}_{1}$ : Managers operating within a control-dominant organizational culture will exhibit more strategy surrogation than managers operating within a flexibility-dominant organizational culture.

\section{Incentive Systems, Performance Measurement and Strategy Surrogation}

Incentive systems have been examined from different dimensions in the accounting literature. For example, reporting structures may be classified as vertical incentive systems where team members report observations of their peers' efforts to management, or horizontal incentive systems that allow team members to directly control the actions of each other. As the level of team identity increases, the horizontal approach becomes more effective relative to the vertical approach (Towry, 2003). Measuring how employees react to incentives is very important to performance measurement, and most importantly to the SPMS (Chenhall, 2005; Burney \& Widener, 2013).

Burney and Widener (2013) examined whether the extent to which an SPMS is coupled with strategy affects employee performance indirectly through motivational characteristics such as perceived self-efficacy and perceived psychological contract. Their study showed that properly aligning an SPMS-based incentives plan tightly with strategy facilitates internalized motivated behaviors (Burney \& Widener, 2013). The ultimate goal of the SPMS is to translate overall organizational strategy, which is intangible, into tangible objectives and measures, and to ensure that organizational outcomes are improved through a better and clearer communication of an organization's strategy to its employees (Kaplan \& Norton, 1996). To achieve this goal, employee incentive systems often are linked to the SPMS (Cianci et al., 2013). 
Incentive systems are used to draw attention to, motivate, direct and redirect employees' performance in an organization in order to achieve an overall organizational goal (Baiman, 1990; Towry, 2003). Some argue that incentive systems improve performance; some argue that incentive systems reduce performance, and some argue that the presence of incentive systems has no effect on performance (Bonner \& Sprinkle, 2002; Burney \& Widener, 2013; Cianci et al., 2013; Pratt \& Awasthi, 1990; Tuttle \& Burton, 1999; Wright \& Anderson, 1989).

The effect of incentives depends on the ability of the decision-maker and the difficulty of the job tasks, not merely on the type and size of the bonus offer (Libby \& Lipe, 1992). Cognitive evaluation theory suggests that incentives can decrease effort and task performance by focusing attention on the external rewards related to a task, which ultimately decreases intrinsic motivation (Bonner \& Sprinkle, 2002; Deci et al., 1981; Dillard \& Fisher, 1990). Alternatively, the pressure-arousal-performance framework establishes that incentives, feedback, and justification generate pressures for decision-making and can lead to either better or worse performance depending on other psychological factors (Ashton, 1990; Baumeister, 1984, 1986). Thus, generalizing the effects of incentive systems on performance measurement across different organizational environments is difficult (Pratt \& Awasthi, 1990). As a result of this difficulty, more research that examines the relationship between different types of incentive systems and performance measurement in different organizational settings is needed (Bonner \& Sprinkle, 2002).

Strategy surrogation occurs when incentive compensation increases the salience of the incentivized measures of performance (Choi et al., 2012; Ijiri, 1975). Specifically, Choi et al. (2012) investigate the influence of incentive compensation on managers' propensity to use compensated measures as surrogates for strategic constructs. Their findings suggest that compensating managers based on a single measure of a strategic construct increases their propensity to use the compensated measure as a surrogate for the construct compared to compensating managers with multiple measures of a strategic construct.

Employees exhibit an increase in productivity of approximately 20 percent when they are paid using a piece rate incentive system rather than 
a high fixed wage (Shearer, 2004). The lowest weighted productivity scores occur when there is no incentive or only a creativity incentive (Kachelmeier, et al. 2008). Kachelmeier et al. (2008) suggest that the quantity of incentives will increase total quantity, and creativity incentives will increase average creativity; however, combining the two may not necessarily increase productivity (Kachelmeier et al., 2008).

Pay-for-performance incentive compensation can be used to motivate additional cognitive effort, but that effort may not translate into optimum outcome for the organization (Libby \& Lipe, 1992). Depending on the sensitivity of the cognitive process and outcome of the increased effort, increased pressure resulting from the pay-for-performance incentive may cause counterproductive results (Ashton, 1990; Kennedy, 1995). Managers may decide to redirect their effort to optimize their personal incentives by not showing any initiative to see beyond the measures that have been linked to the SPMS. It is practically impossible for an organization to accurately translate all its strategy into tangible objectives and performance metrics (Burney \& Widener, 2013). Hence, fixed pay compensation motivates managers to engage in actions that are consistent with overall organizational strategic objectives and provides managers autonomy to use their initiative in order to achieve strategic objectives. Additionally, fixed pay compensation can be used to build trust between the managers and the organization, because managers equate fixed pay with an increased level of trust; i.e., they are trusted to do their job without additional incentives that are associated with pay-for-performance. However, using pay-for-performance linked to the SPMS can be perceived by managers as a way of enforcing the use of SPMS, which may reduce innovativeness and creativity of the managers.

The type of incentive system, fixed pay or pay-for-performance, may affect managers' propensity to exhibit strategy surrogation. Specifically, using the psychology-based Theory of Inattentional Blindness, managers that are compensated by fixed pay are expected to surrogate less than managers that are compensated by a pay-for-performance scheme. Pay-forperformance may encourage managers to focus more on the measures of performance in an attempt to optimize their incentives. Hence, managers will concentrate on the metrics rather than look beyond the metrics. However, when managers are compensated using fixed pay, they are expected to be more likely to rely on their intrinsic motivation to perform their job because 
there is little incentive for them to over focus on the metrics of performance measurements. This implies that the managers operating under a payfor-performance scheme are expected to surrogate more than managers operating under a fixed pay incentive compensation. Thus, the following hypothesis is proposed:

$\mathbf{H}_{2}$ : Managers operating under a pay-for-performance incentive compensation will exhibit more strategy surrogation than managers operating under a fixed pay compensation.

Inattentional blindness suggests that employees will not notice salient and important events outside the scope of established performance measures while they are trying to focus on performance measures (Simons \& Chabris, 1999; Simons, 2000). Thus, when managers focus on a performance measure under a pay-for-performance incentive compensation and they do not see beyond performance measures, their propensity to exhibit strategy surrogation should be greater when the organization operates under a control-dominant culture compared to a flexibility-dominant culture. This is expected because a control-dominant culture encourages conformity, formality, and rigidity, and a flexibility-dominant culture encourages adaptability, spontaneity, and responsiveness. Additionally, pairing a pay-for-performance incentive compensation with a control-dominant organizational culture introduces another form of pressure on managers. This may make managers think that as long as they satisfy the pay-forperformance requirements, they have no additional obligation to ensure that the overall organizational strategic objectives are met.

Managers may exhibit strategy surrogation consciously or subconsciously. Managers could consciously surrogate because managers may not be interested in paying attention to anything other than their performance metrics. This implies that there is no incentive for managers to see beyond the metrics of performance measurement. However, managers could subconsciously surrogate as a result of excessive pressure resulting from the combination of a control-dominant culture and a payfor-performance incentive compensation. A pay-for-performance incentive may motivate additional cognitive effort by the managers, but this may not necessarily translate into the outcome the organization expects. Similarly, pay-for-performance may encourage managers to be innovative, but 
the innovation may be more toward managers' personal benefits rather than organizational strategic objectives. Hence, managers will be more likely to surrogate when they are under a pay-for-performance incentive compensation than when they are under a fixed pay incentive scheme, and a flexibility-dominant culture will be more likely to reduce the propensity to exhibit surrogation. Thus, the next hypothesis is:

$\mathbf{H}_{3}$ : A flexibility-dominant culture will reduce strategy surrogation more under a fixed pay scheme than under a pay-for-performance scheme compared to a control-dominant culture.

\section{EXPERIMENTAL METHOD AND DESIGN}

\section{Participants}

To examine these hypotheses, an online experiment using 80 MTurk workers as proxies for managers was conducted. The participants were randomly assigned to four treatment conditions, with 20 participants per condition. All participants in this study were paid $\$ 2.50$ for participating in this study, as well as additional compensation up to a total of $\$ 9.00$ depending on their randomly assigned condition and their decisions. The majority of the participants were male (65\%). Most participants were between 31-40 years old (44\%), with others aged 21-30 (35\%), age 41-50 (13\%), and over age $50(9 \%)$. Most participants (46\%) had a Bachelor's degree, $29 \%$ had a high school diploma or equivalent, $19 \%$ had an Associate degree, $5 \%$ have a Master's degree, and 1\% had a Doctorate. Most participants (36\%) had 11-20 years of work experience, $28 \%$ had 6-10 years of work experience, $16 \%$ had $0-5$ years of work experience, $15 \%$ had $21-30$ years of work experiment, and $5 \%$ had over 30 years of work experience.

\section{Experimental Design and Task}

This study utilized a $2 \times 2$ between-participants experimental design that manipulates organizational culture and the type of compensation scheme. Specifically, the study manipulated the organizational culture by describing a scenario in which an organization has either a control-dominant culture that values stability and accountability or a flexibility-dominant culture that values invention and innovation. The study also manipulated incentive 
schemes by offering participants either fixed pay or pay-for-performance compensation. The participants were provided a hypothetical case about the company and were required to make some decisions. Specifically, the study consisted of two parts. In the first part, the participants were asked to read a short case scenario ${ }^{1}$ and at the end of the case, they were asked to make some decisions. In the second part, participants were asked several post-study questions and several demographic questions.

The experiment was an online based study administered via the Qualtrics software and disseminated through MTurk. The opening screen is the informed consent page, which was approved by the IRB. If they agreed to participate, then participants proceeded to the transition screen, which further asked them if they have properly read the information on the consent page. At this point, participants could decide to go back to read the consent page again or move to the next page, which is the screening page. The screening page asks participants about their age and the general payment instructions that were included in the informed consent page. The general payment screening question asked the participants how much they are going to be paid for participating in the study. All participants were paid $\$ 2.50$, as well as additional research compensation up to a total of $\$ 9$ based on their compensation scheme and decisions. The participants were screened if they were less than eighteen years of age or they failed the screening question about payment instructions. Following the screening page is the introduction and instructions page. On this page, the participants were asked to assume they are the General Manager of Sparky City's Water Treatment Plant and in charge of making changes to the water treatment process to reduce cost for the coming year. Participants were informed of the conversion rate of their compensation and the instructions on how to receive their payment for this study. A comprehension check question about their specific incentive compensation scheme was asked before participants are able to proceed to the case scenario. The comprehension check question asks the participants, "Which type of additional research compensation are you eligible to receive? YOU MUST ANSWER THIS QUESTION CORRECTLY TO CONTINUE PARTICIPATING IN THE STUDY." Half of participants were randomly assigned to the fixed pay compensation scheme, and the other half were randomly assigned to the pay-for-performance bonus, which is $20 \%$ of the total cost savings to the plant.

1 This instrument is adapted from Akinyele, Arnold, Demek and Tian's 2019 working paper. I would like to thank the authors for allowing me to adapt the case scenario for this study. 
The case scenario highlights that the Water Treatment Plant is responsible for treating the water with chemicals to make it safe for use and consumption by the residents of Sparky City. A lower quality water supply may seriously affect very old, very young, or health impaired individuals, although it is never possible to make the water $100 \%$ safe. Yet, it still is the responsibility of the Water Treatment Plant to ensure that the water is safe for use. Sparky's average number of microorganisms per billion gallons of water over the past three years was within the acceptable range. The Water Treatment Plant is planning to reduce operating costs and is considering changing the chemicals used to treat water. A consultant had provided nine different alternatives, all of which are within acceptable range quantitatively, but may have negative quality implications. As the General Manager, the participant must decide which water treatment alternative to implement based on this scenario.

\section{Independent Variables}

\section{Compensation scheme}

In this study, an experimental currency called "Lira" was used. Lira is converted into U.S. dollars at a rate of $\$ 1$ for every 20,000 Lira, and participants are paid in cash at the end of the study through their MTurk accounts. The amount participants earn depends on their randomly assigned compensation plan as well as their decision on the water treatment alternative to be implemented. The participants in the fixed salary condition were paid 100,000 Lira, which was converted to U.S. dollars at the end of the experiment. The participants in the performance bonus condition were paid 20 percent of the total cost savings to the plant.

\section{Organizational culture}

Half of the participants were randomly assigned to the treatment condition with a control-dominant organizational culture, and the remaining half were randomly assigned to the treatment condition with a flexibilitydominant organizational culture. In the control-dominant organizational culture condition, participants are informed in the scenario that the Sparky City Council is known to be controlling and rigid with their decisions related to cost saving. The City Council strives to maximize cost saving regardless of the warning from the consultant, as long as the alternative decision is within an acceptable range for standards of water quality. In the flexibility- 
dominant organizational culture condition, participants are informed in the scenario that the Sparky City Council is known to be flexible and adaptable with their decisions related to cost savings. The City Council strives to maximize cost saving, but also to consider any warning from the consultant.

\section{Dependent Variable}

The main dependent variable in this study is the participant's water treatment alternative to be implemented. The participant can decide between nine different water treatment alternatives, with corresponding cost savings to the plant as well as the microorganisms per billion (percent decrease in water quality).

\section{RESULTS}

\section{Manipulation and Comprehension Checks}

Participants answered a comprehension check question before they begin to read through the case scenario: Which type of additional research compensation are you eligible to receive? Participants must answer this question correctly before they can proceed to the case scenario. The manipulation check was conducted later in the experiment to provide assurance that participants are aware of the facts that are vital to the successful operationalization of the variable. To verify the manipulation of the organizational culture, participants were asked to indicate the level of their agreement/disagreement with the following statements: (1) Sparky City Council is known to be controlling and rigid with their decisions related to cost saving; (2) Sparky City Council focuses on making decisions that are within an acceptable range for standards of water quality, and considers only quantifiable metrics in their decision making process; (3) Sparky City Council is known to be flexible and adaptable with their decisions related to cost savings; (4) Sparky City Council focuses on making decisions that are within an acceptable range for standards of water quality, and considers quantifiable metrics and qualitative factors in their decision-making process. Statements 3 and 4 were reverse coded. See Table 1 for the descriptive statistics of the manipulation checks and the results of t-tests comparing the answers of those in the flexibility-dominant culture to those in the controldominant culture for each question. The results of the analysis show that the 
organizational culture is significant for all the manipulation checks, which indicates the strength of the manipulation checks.

Table 1: Organizational Culture Manipulations

Descriptive Statistics and Test of Differences

\begin{tabular}{|c|c|c|c|c|}
\hline Descriptions & $\begin{array}{l}\text { Organizational } \\
\text { Culture }\end{array}$ & $\begin{array}{l}\text { Mean } \\
(\mathrm{SD}) \\
{[n]}\end{array}$ & $\mathbf{t}$ & $\begin{array}{c}\text { Sig. } \\
(2 \\
\text { tailed })\end{array}$ \\
\hline \multirow[t]{2}{*}{$\begin{array}{l}\text { Sparky City Council is known to be } \\
\text { controlling and rigid with their decisions } \\
\text { related to cost saving }\end{array}$} & Control-dominant & $\begin{array}{c}6.35 \\
(1.292) \\
{[40]}\end{array}$ & \multirow{2}{*}{10.366} & \multirow[b]{2}{*}{$<.001$} \\
\hline & $\begin{array}{l}\text { Flexibility- } \\
\text { dominant }\end{array}$ & $\begin{array}{c}2.58 \\
(1.907) \\
{[40]}\end{array}$ & & \\
\hline \multirow{2}{*}{$\begin{array}{l}\text { Sparky City Council focuses on making } \\
\text { decisions that are within an acceptable } \\
\text { range for standards of water quality, and } \\
\text { considers only quantifiable metrics in } \\
\text { their decision making process }\end{array}$} & Control-dominant & $\begin{array}{c}5.70 \\
(1.728) \\
{[40]}\end{array}$ & \multirow{2}{*}{2.647} & \multirow{2}{*}{.010} \\
\hline & $\begin{array}{l}\text { Flexibility- } \\
\text { dominant }\end{array}$ & $\begin{array}{c}4.65 \\
(1.819) \\
{[40]}\end{array}$ & & \\
\hline \multirow[t]{2}{*}{$\begin{array}{l}\text { Sparky City Council is known to be } \\
\text { flexible and adaptable with their decisions } \\
\text { related to cost savings (Reverse coded) }\end{array}$} & Control-dominant & $\begin{array}{c}5.88 \\
(1.636) \\
{[40]}\end{array}$ & \multirow{2}{*}{10.796} & \multirow{2}{*}{$<.001$} \\
\hline & $\begin{array}{l}\text { Flexibility- } \\
\text { dominant }\end{array}$ & $\begin{array}{c}2.20 \\
(1.400) \\
{[40]}\end{array}$ & & \\
\hline \multirow{2}{*}{$\begin{array}{l}\text { Sparky City Council focuses on making } \\
\text { decisions that are within an acceptable } \\
\text { range for standards of water quality, } \\
\text { and considers quantifiable metrics and } \\
\text { qualitative factors in their decision- } \\
\text { making process (Reverse coded) }\end{array}$} & Control-dominant & $\begin{array}{c}4.10 \\
(2.122) \\
{[40]}\end{array}$ & \multirow[b]{2}{*}{5.648} & \multirow[b]{2}{*}{$<.001$} \\
\hline & $\begin{array}{l}\text { Flexibility- } \\
\text { dominant }\end{array}$ & $\begin{array}{c}2.03 \\
(.947) \\
{[40]}\end{array}$ & & \\
\hline
\end{tabular}

\section{Descriptive Statistics}

The focus of this study was to examine managers' propensity to exhibit strategy surrogation, which is operationalized by the water treatment alternative the manager decides to implement. Table 2 Panel A presents descriptive statistics of the managers' decisions, and Figure 1 shows a graphical representation of the results. In the fixed pay condition, the mean (standard deviation) of the water treatment decision is 4.85 (2.58) when employees are operating under a control-dominant organizational culture, and 4.26 (2.38) when employees are operating under a flexibility-dominant organizational culture. In the pay-for-performance incentive pay condition, the mean (standard deviation) of the alternative water treatment decision 
is 7.20 (2.26) when employees are operating under a control-dominant organizational culture, and 6.76 (2.41) when employees are operating under a flexibility-dominant organizational culture. The mean (standard deviation) of the total fixed pay is 4.56 (2.47); and the mean (standard deviation) of the total pay-for-performance is 6.98 (2.32). Similarly, the mean (standard deviation) of the total control-dominant culture is 6.03 (2.68); and the mean (standard deviation) of the total flexibility-dominant culture is 5.58 (2.68).

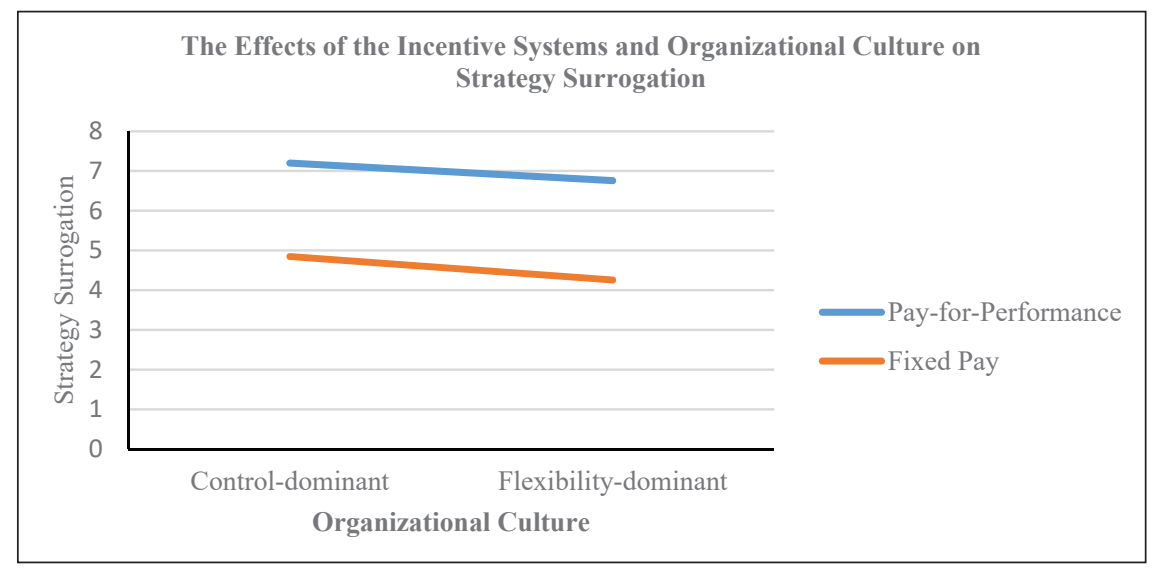

Figure 1: Interaction Graph

\section{Test of Hypotheses}

$\mathrm{H} 1$ posits that in a control-dominant organizational culture, managers may find it difficult to consider salient and potentially relevant information when making decisions compared to managers operating in a flexibilitydominant organizational culture. Specifically, managers operating in a control-dominant organizational culture will exhibit more strategy surrogation than managers operating in a flexibility-dominant organizational culture. To test this conclusion statistically, Table 2 Panel B reports the overall ANOVA findings. The results show that managers operating in a control-dominant organizational culture do not surrogate more than managers operating under a flexibility-dominant organizational culture ( $\mathrm{F}$ $=0.90, \mathrm{p}=0.345$, two-tailed).

$\mathrm{H} 2$ posits that managers that are compensated by a pay-for-performance scheme are expected to surrogate more than managers that are compensated 
by a fixed pay scheme. Managers compensated with a pay-for-performance scheme are more likely to concentrate on the metrics of the performance measurement rather than to look beyond the metrics because they are unintentionally blinded to anything other than the metrics. Table 2 Panel $\mathrm{B}$ shows that managers operating under a pay-for-performance incentive compensation statistically surrogate more than managers operating under a fixed incentive compensation ( $\mathrm{F}=20.22, \mathrm{p}<0.001$, two-tailed).

$\mathrm{H} 3$ posits that employees working in a flexibility-dominant culture will exhibit less strategy surrogation under a fixed pay scheme than under a pay-for-performance scheme compared to employees working in a control-dominant culture. The Inattentional Blindness Theory suggests that employees will not notice salient and important events outside the scope of established performance measures while they are trying to focus their attention on performance measures. It is predicted that a flexibility-dominant culture will reduce the propensity of employees to surrogate, and it will reduce it more under a fixed pay scheme than under a pay-for-performance scheme compared to a control-dominant culture. The results do not support the interaction hypothesis $(\mathrm{F}=0.02, \mathrm{p}=0.891$, two-tailed $)$.

Table 2: Main Results - Alternative Decisions

Panel A: Descriptive Statistics - Mean (Standard Deviation) [Sample Size]

\begin{tabular}{lccc}
\hline \multicolumn{4}{c}{ Organizational Culture } \\
\hline Incentive Pay & Control-dominant & $\begin{array}{c}\text { Flexibility- } \\
\text { dominant }\end{array}$ & Total \\
\hline Fixed Pay & 4.85 & 4.26 & 4.56 \\
& $(2.58)$ & $(2.38)$ & $(2.47)$ \\
& {$[20]$} & {$[19]$} & {$[39]$} \\
\hline Pay for Performance & 7.20 & 6.76 & 6.98 \\
& $(2.26)$ & $(2.41)$ & $(2.32)$ \\
& {$[20]$} & {$[21]$} & {$[41]$} \\
\hline Total & 6.03 & 5.58 & 5.80 \\
& $(2.68)$ & $(2.68)$ & $(2.67)$ \\
& {$[40]$} & {$[40]$} & {$[80]$} \\
\hline
\end{tabular}


Panel B: Results of ANOVA: The Effects of the Incentive Systems and Organizational Culture on Strategy Surrogation

\begin{tabular}{lccccc}
\hline \multicolumn{1}{c}{ Source } & $\begin{array}{c}\text { Type III Sum } \\
\text { of Squares }\end{array}$ & d.f. & $\begin{array}{c}\text { Mean } \\
\text { Square }\end{array}$ & F-Ratio & p-value \\
\hline Incentive Pay & 117.41 & 1 & 117.41 & 20.22 & $<0.001$ \\
\hline Organizational Culture & 5.25 & 1 & 5.25 & 0.90 & 0.345 \\
\hline $\begin{array}{l}\text { Incentive Payx Organizational } \\
\text { Culture }\end{array}$ & 0.11 & 1 & 0.11 & 0.02 & 0.891 \\
\hline Error & 441.24 & 76 & 5.81 & & \\
\hline Total & 3254.00 & 80 & & & \\
\hline
\end{tabular}

\section{CONCLUSION}

This study examined the effect of an important organizational context, specifically organizational culture, and different types of compensation schemes on strategy surrogation. Strategy surrogation occurs when managers focus on the measures in the SPMS on which they are compensated and completely or partially lose focus on the overall strategic objectives of the organization (Choi et al., 2012, 2013). According to the competing values model, organizational culture can be characterized as control-dominant that values stability and accountability, or flexibility-dominant that values invention and innovation (Quinn \& McGrath, 1985; Quinn, 1988; Quinn $\&$ Rohrbaugh, 1983). This study hypothesizes the main effect that managers operating in a control-dominant organizational culture will exhibit more strategy surrogation than managers operating in a flexibility-dominant organizational culture. Additionally, this study proposed that individuals paid for performance would exhibit more surrogation than individuals paid a fixed wage. Finally, this study hypothesizes that a flexibility-dominant culture will reduce strategy surrogation more under a fixed pay scheme than a pay-for-performance scheme compared to a control-dominant culture.

The study uses a 2 (culture: control-dominant vs. flexibility-dominant) x 2 (compensation scheme: fixed pay vs. pay-for-performance) betweenparticipants experimental design. An online experiment was conducted using 80 Amazon Mechanical Turk (MTurk) workers as proxies for managers. The study consisted of two parts. In the first part, the participants were asked to read a short case scenario, and at the end of the case, they are asked to 
make some decisions. In the second part, participants were asked several post-study questions and demographic questions. The participants were randomly assigned to four conditions. All participants were paid $\$ 2.50$ for participating, and additional research compensation up to a total of $\$ 9.00$ depending on their randomly assigned condition and their decisions.

Consistent with prior literature (Choi et al., 2012), the results of this study show that managers using a pay-for-performance surrogate are compensated more than managers using a fixed pay. This result is supported by the Inattentional Blindness Theory. The results show that employees operating under a pay-for-performance scheme will be less likely to notice relevant information that is beyond their current focus when making decisions, compared to employees operating under a fixed pay scheme. There is no support for the hypothesis that managers operating in a controldominant organizational culture will exhibit more strategy surrogation than managers operating in a flexibility-dominant culture.

This study contributes to research and practice in several ways. First, this study shows that employees compensated under a pay-for-performance scheme significantly surrogate more than employees compensated under a fixed pay scheme. The results corroborate prior research findings in managerial accounting on strategy surrogation. Specifically, this study confirms prior findings by Choi et al. (2012) that employees compensated on a single measure of a strategic construct with a pay-for-performance scheme exacerbate more surrogation of the construct relative to employees that receive a fixed pay scheme. Second, this study extends prior research by exploring whether organizational culture, as a form of informal management control systems, influences strategy surrogation. The results do not indicate that organizational culture is a driving force. Third, this study examines whether the type of organizational culture moderates the effect of incentive system on strategy surrogation. This study contributes to the incentives literature by highlighting conditions under which incentive systems can be used to refocus employees' attention.

The results have certain limitations that suggest several avenues for future research. One reason for not finding support for the first hypothesis, about managers operating in a control-dominant organizational culture, could be associated with the saliency of organizational culture manipulation. 
It could be that the participants were not able to internalize the different types of organizational culture. It is also possible that participants in the study may have focused more on the immediate impact of the payment scheme rather than on the broader impact of the organization culture. Future research should examine the effect of organizational culture on strategy surrogation in other contexts to ensure that the manipulation of organizational culture was not overpowered by the short term effects of the reward system used in my study. Future research also should examine other institutional factors that can influence employees' propensity to exhibit strategy surrogation. Similarly, future research also can examine other important aspects of managerial accounting research that the type of organizational culture can impact.

Strategy surrogation is an important, but difficult to examine, construct in managerial accounting (Choi et al., 2012, 2013). Most previous studies have used laboratory experiments to examine strategy surrogation. Future research can examine the concept of strategy surrogation using a different research approach such as field experiments or qualitative methods. Future research could examine this research question using a more controlled research environment. Regardless of the limitations of this study, this study contributes to our understanding of strategy surrogation in the managerial accounting literature

\section{REFERENCES}

Ashton, R. H. (1990). Pressure and performance in accounting decision settings - Paradoxical effects of incentives, feedback, and justification. Journal of Accounting Research, 28(S), 148-180.

Baiman, S. (1990). Agency research in managerial accounting: A second look. Accounting, Organizations and Society, 15(4), 341-371.

Baumeister, R. (1984). Choking under pressure: Self-consciousness and paradoxical effects of incentives on skillful performance. Journal of Personality and Social Psychology, 46(3), 610-620. 
Baumeister, R. (1986). A review of paradoxical performance effects: Choking under pressure in sports and mental tests. European Journal of Social Psychology, 16, 361-383.

Bedford, N. (1968). The foundations of accounting measurement. Journal of Accounting Research, 6(2), 270-282.

Bititci, U., Garengo, P., Dörfler, V., \& Nudurupati, S. (2012). Performance measurement: Challenges for tomorrow. International Journal of Management Reviews, 14(3), 305-327.

Bititci, U., Mendibil, K., Nudurupati, S. S., \& Garengo, P. (2006). Dynamics of performance measurement and organizational culture. International Journal of Operations \& Production, 26(12), 1325-1350.

Bonner, S. E., \& Sprinkle, G. B. (2002). The effects of monetary incentives on effort and task performance: Theories, evidence, and a framework for research. Accounting, Organizations and Society, 27(4-5), 303-345.

Burney, L. L., \& Widener, S. K. (2013). Behavioral work outcomes of a strategic performance measurement system-based incentive plan. Behavioral Research in Accounting, 25(2), 115-143.

Campbell, D., Datar, S. M., Kulp, S. L., \& Narayanan, V. G. (2015). Testing strategy with multiple performance measures: Evidence from a balanced scorecard at Store24. Journal of Management Accounting Research, 27(2), 41.

Chenhall, R. H. (2005). Integrative strategic performance measurement systems, strategic alignment of manufacturing, learning and strategic outcomes: An exploratory study. Accounting, Organizations and Society, 30(5), 395-422.

Choi, J., Hecht, G. W., \& Tayler, W. B. (2012). Lost in translation: The effects of incentive compensation on strategy surrogation. Accounting Review, 87(4), 1135-1163. 
Choi, J., Hecht, G. W., \& Tayler, W. B. (2013). Strategy selection, surrogation, and strategic performance measurement systems. Journal of Accounting Research, 51(1), 105-133.

Cianci, A. M., Kaplan, S. E., \& Samuels, J. A. (2013). The moderating effects of the incentive system and performance measure on managers' and their superiors' expectations about the manager's effort. Behavioral Research in Accounting, 25(1), 115-134.

Cravens, K. S., Oliver, E. G., \& Stewart, J. S. (2015). Workplace culture mediates performance appraisal effectiveness and employee outcomes: A study in a retail setting. Journal of Management Accounting Research, 27(2), 1-34.

Deci, E., Betly, G., Kahle, J., Abrams, L., \& Porac, J. (1981). When trying to win: Competition and intrinsic motivation. Personality and Social Pschology Bulletin, 7(1), 79-83.

Dent, J. F. (1990). Strategy, organization and control: Some possibilities for accounting research. Accounting, Organizations and Society, 15(1-2), $3-25$.

Dent, J. F. (1991). Accounting and organizational cultures: A field study of the emergence of a new organizational reality. Accounting, Organizations and Society, 16(8), 705-732.

Dillard, J. F., \& Fisher, J. G. (1990). Compensation schemes, skill level, and task performance: An experimental examination. Decision Sciences, 21(1), 121-137.

Henri, J.-F. (2006). Organizational culture and performance measurement systems. Accounting, Organizations and Society, 31(1), 77-103.

Ijiri, Y. (1975). Theory of accounting measurement: Studies in accounting research 10. Sarasota, FL: American Accounting Association.

Ittner, C. D., \& Larcker, D. F. (1998). Innovations in performance measurement: Trends and research implications. Journal of Management Accounting Research, 10, 205. 
Johnson, T., \& Broms, A. (2000). Profit beyond measure: Extraordinary results through attention to work and people. New York: Free Press.

Kachelmeier, S. J., Reichert, B. E., \& Williamson, M. G. (2008). Measuring and motivating quantity, creativity, or both. Journal of Accounting Research, 46(2), 341-373.

Kahneman, D., \& Egan, P. (2011). Thinking, fast and slow. New York: Macmillian.

Kaplan, R. S., \& Norton, D. P. (1992). The balanced scorecard: Measures that drive performance. Harvard Business Review, 70(1), 71-79.

Kaplan, R. S., \& Norton, D. P. (1996). The balanced scorecard: Translating strategy into action. Harvard Business School Press, 1-311.

Kaplan, R. S., \& Norton, D. P. (2000). Having trouble with your strategy? Then map it. Harvard Business Review, 78(5), 167-176.

Kennedy, J. (1995). Debiasing the curse of knowledge in audit judgment. The Accounting Review, 70(2), 249-273.

Kerlinger, F. N., \& Lee, H. B. (2000). Foundations of behavioral research (4th ed.). New York: Holt.

Libby, R., \& Lipe, M. G. (1992). Incentives, effort, and the cognitive processes involved in accounting-related judgments. Journal of Accounting Research, 30(2), 249-273.

Pratt, J., \& Awasthi, V. (1990). The effects of monetary incentives on effort and decision performance: The role of cognitive characteristics. The Accounting Review, 65(4), 797-811.

Quinn, R.E. (1988). Beyond rational management: Mastering the paradoxes and competing demands of high performance (1st ed.). San Francisco: Jossey-Bass Inc. Publishers. 
Quinn, R. E., \& McGrath, M. (1985). The transformation of organizational cultures: A competing values perspective. Organizational Culture, 315-334.

Quinn, R. E., \& Rohrbaugh, J. (1983). A spatial model of effectiveness criteria: Towards a competing values approach to organizational analysis. Management Science, 29(3), 363-378.

Shearer, B. (2004). Piece rates, fixed wages and incentives: Evidence from a field experiment. The Review of Economic Studies, 71(2), 513-534.

Simons, D. (2000). Attentional capture and inattentional blindness. Trends in Cognitive Sciences, 4(4), 147-155.

Simons, D. J., \& Chabris, C. F. (1999). Gorillas in our midst: Sustained inattentional blindness for dynamic events. Perception, 28, 1059-1074.

Towry, K. L. (2003). Control in a teamwork environment - The impact of social ties on the effectiveness of mutual contracts. Accounting Review, 78(4), 1069-1095.

Tuttle, B., \& Burton, F. G. (1999). The effects of a modest incentive on information overload in an investment analysis task. Accounting, Organizations and Society, 24(8), 673-687.

Webb, R. A. (2004). Managers' commiment to the goals contained in strategic performance measurement system. Contemporary Accounting Research, 21(4), 925-958.

Wright, W. F., \& Anderson, U. (1989). Effects of situation familiarity and financial incentives on use of the anchoring and adjustment heuristic for probability assessment. Organizational Behavior and Human Decision Processes, 44(1), 68-82. 